\title{
Enhancement of structural and optical properties of transparent sodium zinc phosphate glass-ceramics nano composite
}

\author{
M. A. Farag ${ }^{1}$ A. Ibrahim² M. Y. Hassaan' ${ }^{1}$ R. M. Ramadan ${ }^{3}$
}

Received: 8 June 2021 / Revised: 20 December 2021 / Accepted: 6 February 2022 / Published online: 3 March 2022

(c) The Author(s) 2022

\begin{abstract}
Transparent sodium phosphate glass-ceramics system according to the composition $(55-x) \mathrm{P}_{2} \mathrm{O}_{5} \cdot(30+x) \mathrm{ZnO} \cdot 15 \mathrm{Na}_{2} \mathrm{O}$ where $x=0,2.5,5,7.5$, and 10 was prepared with the melt quenching technique. Different techniques such as XRD and infrared spectroscopy (FTIR) were used to investigate the structure of the studied glass samples and glass-ceramics nano composite. XRD revealed the formation of crystalline phase. The crystalline phase of $\mathrm{Na}_{2} \mathrm{Zn}\left(\mathrm{P}_{2} \mathrm{O}_{7}\right)$ and $\mathrm{Na}_{2} \mathrm{ZnP}_{2} \mathrm{O}_{7} \cdot \mathrm{Zn}_{2} \mathrm{P}_{2} \mathrm{O}_{7}$ has been detected which varies according to the $\mathrm{ZnO}$ concentration. The density increased whereas molar volume decreased as $\mathrm{ZnO}$ content was increased. Optical band gap values, direct and indirect, decreased with increasing $\mathrm{ZnO}$ content revealing that bridging oxygen linkage $\mathrm{Zn}-\mathrm{O}-\mathrm{P}$ present in the glass network. The band gaps were found to be ranging between 3.42 and $3.13 \mathrm{eV}$ for indirect transition and ranging between 4.34 and $4.20 \mathrm{eV}$ for direct transitions. It was concluded that the samples have a strong tendency to be crystallized with increasing $\mathrm{ZnO}$ content in the sample. This crystallization behavior with increasing the $\mathrm{ZnO}$ content affected the structure and optical properties of the prepared samples. In this work, a low cost, wide band gap transparent ceramic with wide range of transparency was prepared and investigated. Such glass-ceramic system is suitable for doping with rare-earth element and/or transition metals for laser and optical devices.
\end{abstract}

Keywords Phosphate glass · Transparent glass-ceramics $\cdot$ UV/visible $\cdot$ FTIR spectroscopy

\section{Introduction}

Transparent glass-ceramics, distinguished by their dual character, emit light as amorphous glasses, while their anisotropy, in addition to other physical and chemical properties, has given rise to their optical parameters, optical dielectric constant, and refractive index [1].

In recent years, scientists had investigated phosphatebased glasses for various technological applications including sealing materials, solid-state electrolytes $[2,3]$, radioactive waste containment [4], laser technologies, medical

M. Y. Hassaan

Myhassaan@yahoo.com

1 Physics Department, Faculty of Science, Al-Azhar University, Nasr CityCairo 11884, Egypt

2 Basic Sciences Department, Faculty of Engineering Science, Sinai University, El Kantara, Egypt

3 Microwave Physics and Dielectrics, Physics Research Institute, National Research Centre, DokkiCairo 12311, Egypt applications such as degradable tissue and bone scaffolds [5], and agro-fertilizers with controlled solubility [6, 7].

Phosphate glasses are suitable for a wide range of applications due to their low melting, softening temperatures, high electrical conductivity, high thermal expansion coefficient, optical characteristics, high thermal stability, and the possibility of adding many glass modifiers which in turn alter their chemical composition [8-11]. Also, phosphate glasses are widely used in high gain laser materials which are used in high-power laser systems due to its ability to be shaped in large-format production, the high solubility of rare-earth ions and transition metals, high damage threshold [12, 13].

Vitreous phosphate glass network is built by linkages between $\mathrm{PO}_{4}$ tetrahedra. These glasses have low chemical durability due to the presence of hygroscopic $\mathrm{P}-\mathrm{O}-\mathrm{P}$ bonds which limits the use of phosphate glasses in many fields. Fortunately, phosphate glasses properties and chemical durability can be improved by adding a modifying oxide such as transition metal oxide $[14,15]$. Many reports have shown that the addition of transition metals (TM) replaces bridging $\mathrm{P}-\mathrm{O}-\mathrm{P}$ bonds with more moisture-resistant $\mathrm{P}-\mathrm{O}-\mathrm{TM}$ bonds. TM can mostly coexist in different oxidation states in the 
glass structure; both semiconducting and magnetic properties can be affected positively by the electronic transfer in between the low- and high-valence states [16].

The glasses containing $45 \mathrm{P}_{2} \mathrm{O}_{5} \mathrm{~mol} \%$ can be melt easily and biocompatible in nature [17]. $\mathrm{Na}_{2} \mathrm{O}$ acts as network modifying oxide, which can depolymerize the glass network by forming nonbridging oxygen (NBO), and decreases the melting temperature.

The study of optical properties of the sodium phosphate glasses shows a wide range of transparency in IR and visible range [18] which candidate these glasses to be host materials for rare-earth elements and transition metals to produce laser cavities and optical filters.

The present study aims to prepare and investigate the effect of $\mathrm{ZnO}$ content and effect of annealing on crystallinity, structure, and optical properties for zinc sodium phosphate glass-ceramic nano composite to be used as a host material for rare-earth ions and/or transition metals used in solid-state lasers and other optical applications.

\section{Experimental}

Glass and glass-ceramics nano composite samples of composition $(55-x) \mathrm{P}_{2} \mathrm{O}_{5} \cdot(30+x) \mathrm{ZnO} .15 \mathrm{Na}_{2} \mathrm{O}$ where $x=0,2.5$, $5,7.5$, and $10 \mathrm{~mol} \%$ were prepared by melting a pure regent of di-ammonium hydrogen orthophosphate, sodium carbonate, and zinc oxide with the proper ratios. The mixture was mixed and grinded in a mortar to produce a fine powder. The homogenous mixture was melted in porcelain coercible at $950{ }^{\circ} \mathrm{C}$ for $1 \mathrm{~h}$ and shacked regularly to insure the mixture homogeneity. To produce glass-ceramics nano composite, the molten mixture was poured in an oven at $350{ }^{\circ} \mathrm{C}$. The furnace was cooled down to room temperature with a step of $1{ }^{\circ} \mathrm{C} / \mathrm{min}$, while the glass samples with the same composition were poured in air between two brass plates. Both group samples were annealed at $150{ }^{\circ} \mathrm{C}$ for $3 \mathrm{~h}$ to reduce the internal stresses and enhance the mechanical stability. The studied samples were grinded in agate-mortar pestle to obtain fine powders to be measured by X-ray diffraction (XRD) and FTIR.

XRD was used to confirm the crystal structure of the prepared samples. XRD patterns were recorded using a Brucker D8 Advanced, with a $\mathrm{CuK} \alpha$ as radiation source $(\lambda \mathrm{CuK} \alpha=0.1540600 \mathrm{~nm})$ and operating at $40 \mathrm{kV}$. Data was taken in step mode, using intervals of $0.02^{\circ}$, over a $2 \theta$ range of $4-70^{\circ}$. The obtained experimental patterns of both glass samples, poured in air and the samples poured in furnace at $350{ }^{\circ} \mathrm{C}$, were compared to standards compiled by Joint Committee on Powder Diffraction and Standards (JCDPS). The structure investigation was performed at room temperature using Bruker vertex 70 FTIR spectrometer in the wavenumber range $400-4000 \mathrm{~cm}^{-1}$. The spectrum of each sample represents an average of 20 scans. The IR spectra were analyzed using the deconvolution method [19, 20].

The glass heat treatment temperature that was chosen according to a previous published paper contains a similar phosphate glass composition prepared at the same conditions in our lab. $T_{\mathrm{g}}$ was found to be around $360^{\circ} \mathrm{C}$ while $T_{\mathrm{c}}$ of such glasses was found to be around $480{ }^{\circ} \mathrm{C}$ [21]. In this work, the samples were poured around $T_{\mathrm{g}}$ and cooled at a slow rate of cooling, which allowed the crystalline phase to be formed. The annealing temperature was $150{ }^{\circ} \mathrm{C}$ to release any thermal stresses inside the formed glass-ceramic.

The density $(\rho)$ was determined at room temperature by using the Archimedes method with toluene as an immersing liquid. The density of each glass sample was taken as the average of at least five samples, with a tolerance of about $\pm 1 \%$. The relative error in the density measurements was found to be $\pm 0.02 \% \mathrm{~g} / \mathrm{cm}^{3}$. The molar volume $\left(V_{\mathrm{m}}\right)$ was calculated using the formula.

$V_{\mathrm{m}}=\sum n_{\mathrm{i}} M_{\mathrm{i}} / \rho$

where $M_{\mathrm{i}}$ is the molecular mass of the oxide $\mathrm{i}$, and $n_{\mathrm{i}}$ is the oxide molar fraction in the glass.

UV-Vis absorption spectra of the polished samples with a constant thickness $( \pm 0.1 \mathrm{~mm})$ were immediately measured using (JASCO V-570 Japan) with wavelength ranged between 190 and $2500 \mathrm{~nm}$.

\section{Result and dissection}

\section{X-ray diffraction results}

The X-ray patterns of the samples poured in furnace are shown in Fig. 1 for the samples $x=0$ and $2.5 \mathrm{~mol} \%$ showed a superposition of broad hump that characteristic the amorphous structure with some other peaks that characteristic to the crystalline phases referred to sodium zinc phosphate represents $\mathrm{Na}_{2} \mathrm{Zn}\left(\mathrm{P}_{2} \mathrm{O}_{7}\right)$ phase (card 87-0499). In order to identify the crystalline phases that appear in the diffraction patterns by using standard procedures, computer analysis is based on the powder diffraction file. This analysis permitted the identification of the crystalline phase present in the prepared samples. The crystallization increases at the expense of the amorphous structure with increasing $\mathrm{ZnO}$ mol\%. Figure 1 shows the appearance of new diffraction peaks started in the composition range $5 \leq \mathrm{ZnO}<10 \mathrm{~mol} \%$ which are related to the crystalline phase $\mathrm{Na}_{2} \mathrm{ZnP}_{2} \mathrm{O}_{7} \cdot \mathrm{Zn}_{2} \mathrm{P}_{2} \mathrm{O}_{7}$ (card 51-0349). The intensity of the second crystalline phase depends on the concentration of $\mathrm{ZnO}$ content up to $7.5 \mathrm{~mol} \%$. At $\mathrm{ZnO}=10 \mathrm{~mol} \%$, the intensity decreases due to disillusion of the crystalline phase in the glass matrix and this means that the sample 


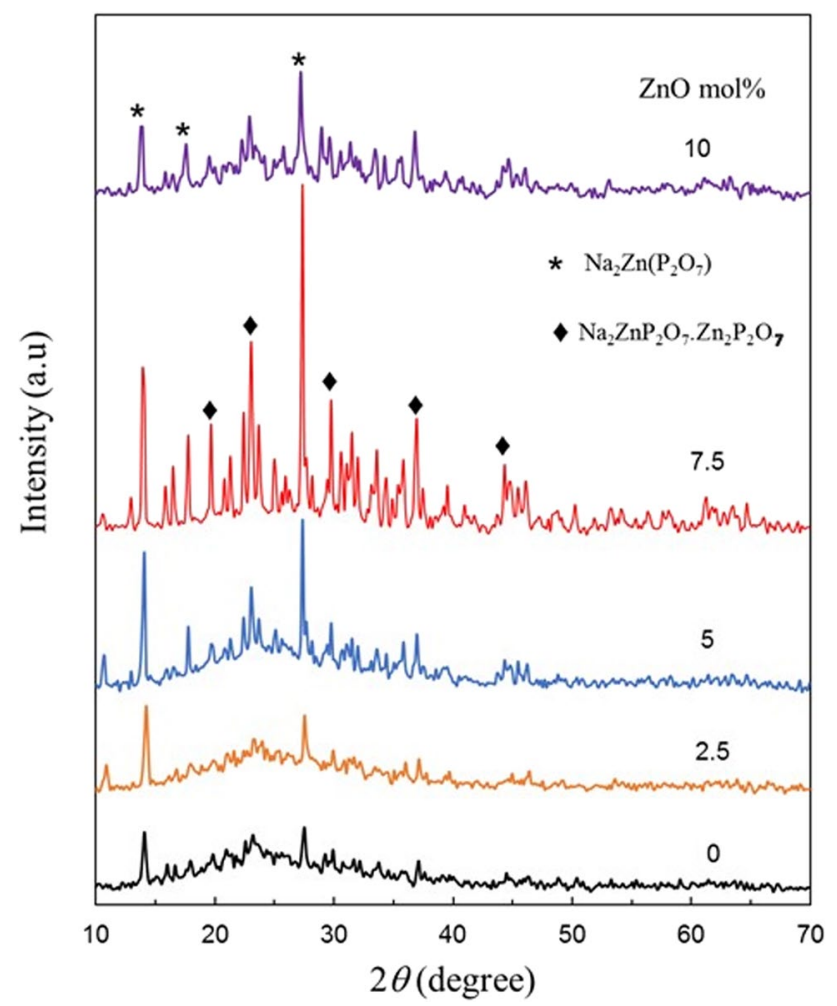

Fig. 1 XRD patterns of glass-ceramics nano composite

has tendency to form amorphous structure depending on $\mathrm{ZnO}$ content increment. The degree of crystallinity was found to suddenly increase with increasing $\mathrm{ZnO}$ concentration reaching a maximum value at $\mathrm{ZnO}=7.5 \mathrm{~mol} \%$, then it starts to decrease at higher $\mathrm{ZnO}$ concentrations. The decrease in crystallinity at $\mathrm{ZnO}>7.5 \mathrm{~mol} \%$ gives good evidence that $\mathrm{ZnO}$ plays the role of glass modifier which forms NBOs in the glass network. The formation of NBOs will increase the disordered which leads to reducing the degree of crystallinity, see Fig. 2.

The crystalline size can be calculated by Scherrer's formula: [22]

$D=\frac{0.94 \lambda}{B \cos \theta}$

where $D$ is the mean grain size, $B$ is the full width at half maximum of the diffraction line radiant (broadening), $\theta$ is the diffraction angle for the diffraction line, and $\lambda$ is the wavelength of the X-ray.

The calculated crystal sizes were found in the nano-meter range and varying by the variation of the $\mathrm{ZnO}$ content. By increasing the $\mathrm{ZnO}$ ratio, the crystal size increases up to $40 \mathrm{~nm}$ in the sample that contains $35 \mathrm{~mol} \% \mathrm{ZnO}$ followed by a decrease with increasing $\mathrm{ZnO}$ content to reach $29 \mathrm{~nm}$ in the sample that contains $45 \mathrm{ZnO}$. The relation between $\mathrm{ZnO}$ and crystal size is shown in Fig. 2.
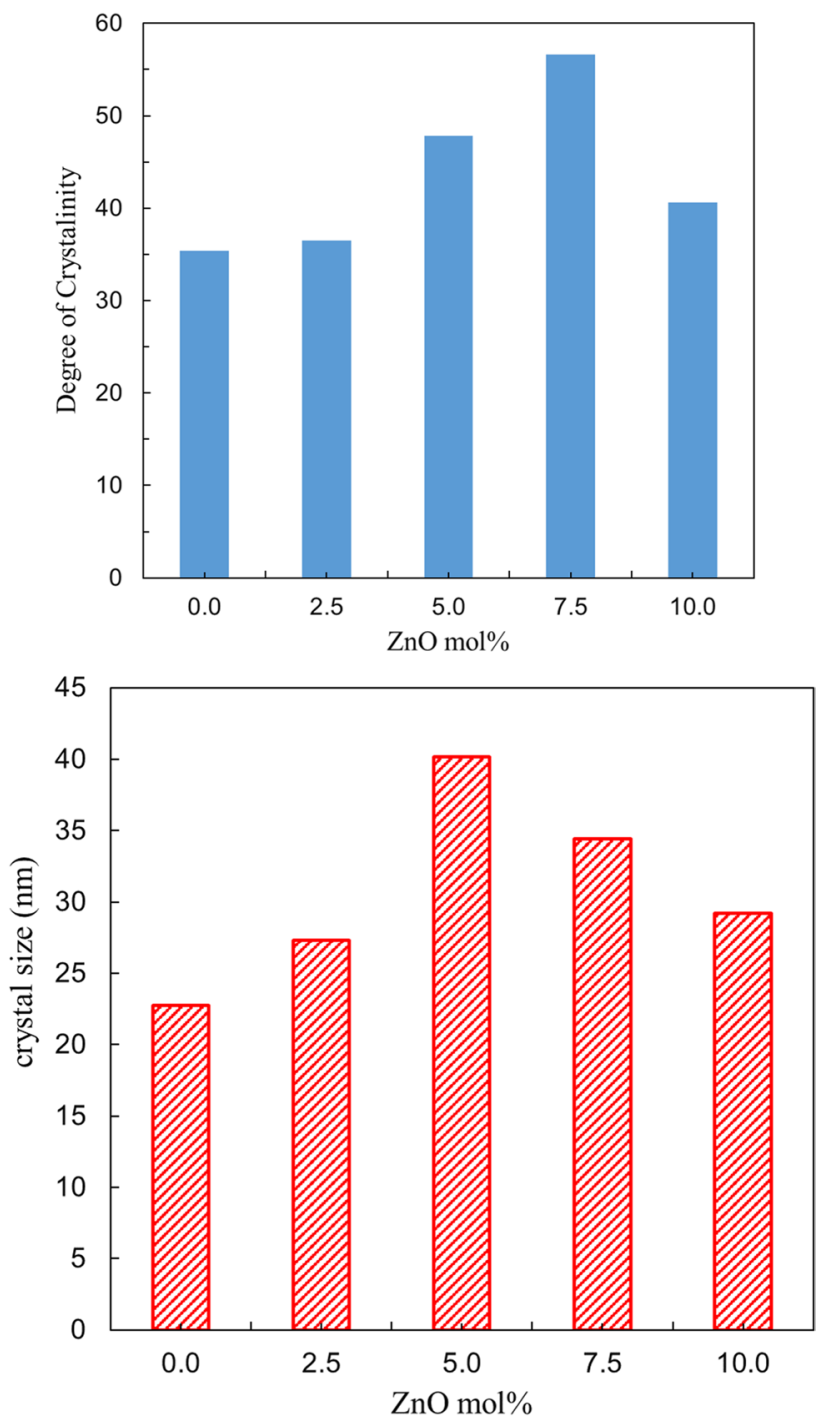

Fig. 2 The degree of crystallinity and crystal size of glass-ceramics nano composite

\section{FTIR results}

Figure 3 shows the measured IR spectra of the samples under investigation. The spectra showed main peaks, based on visual judgment, and around 500, 731, 900, 1091, and $1245 \mathrm{~cm}^{-1}$. The IR spectra of the samples under investigation were normalized and deconvoluted. The analysis of the spectra demonstrates the existence of some peaks located around 480, 502, 548, 728, 785, 898, 989, 1083, 1156, 1252, and $1312 \mathrm{~cm}^{-1}$. Figure 4 shows the spectrum of the sample $\left(55 \mathrm{P}_{2} \mathrm{O}_{5} \cdot 30 \mathrm{ZnO} .15 \mathrm{Na}_{2} \mathrm{O}\right)$ after deconvolution analysis.

Normally, the pentavalent of phosphate ion, $\mathrm{PO}_{4}$ tetrahedra shares three corners with the surroundings tetrahedra by sharing three oxygen atoms, bridging oxygen, forming branched polymer, long chains, or rings of interconnected $\mathrm{PO}_{4}$ tetrahedra, while the fourth oxygen atom 


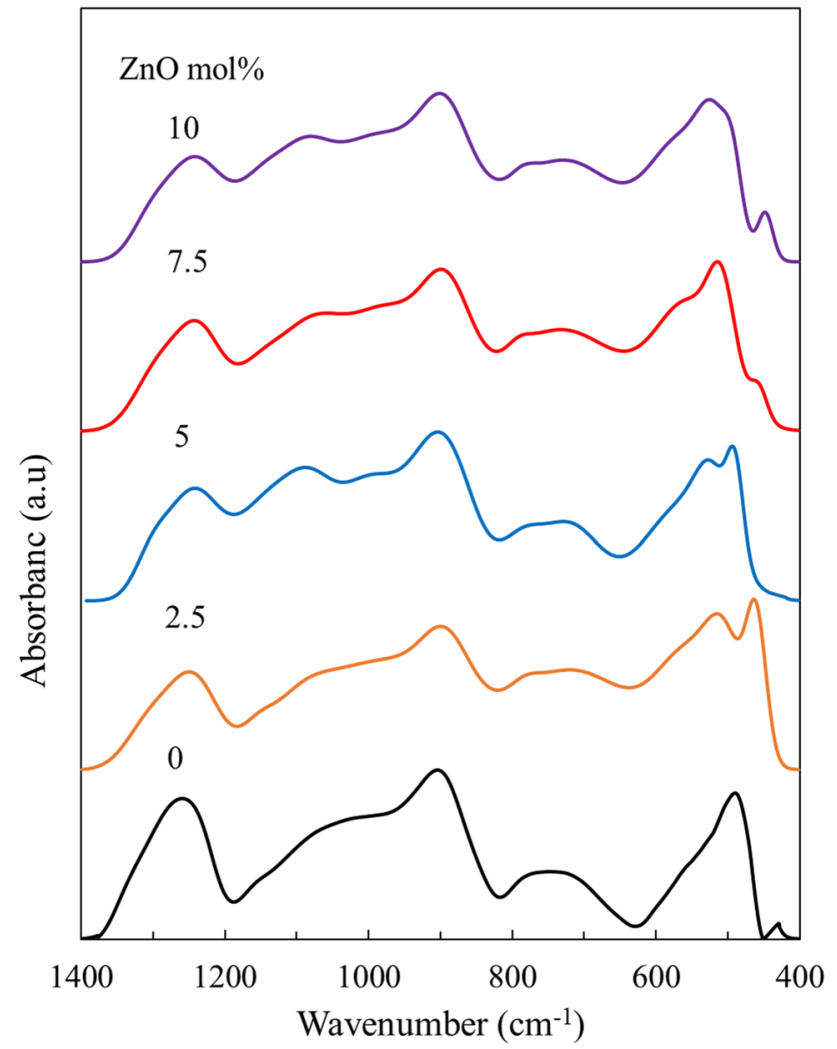

Fig. 3 FTIR spectra of glass-ceramics nano composite

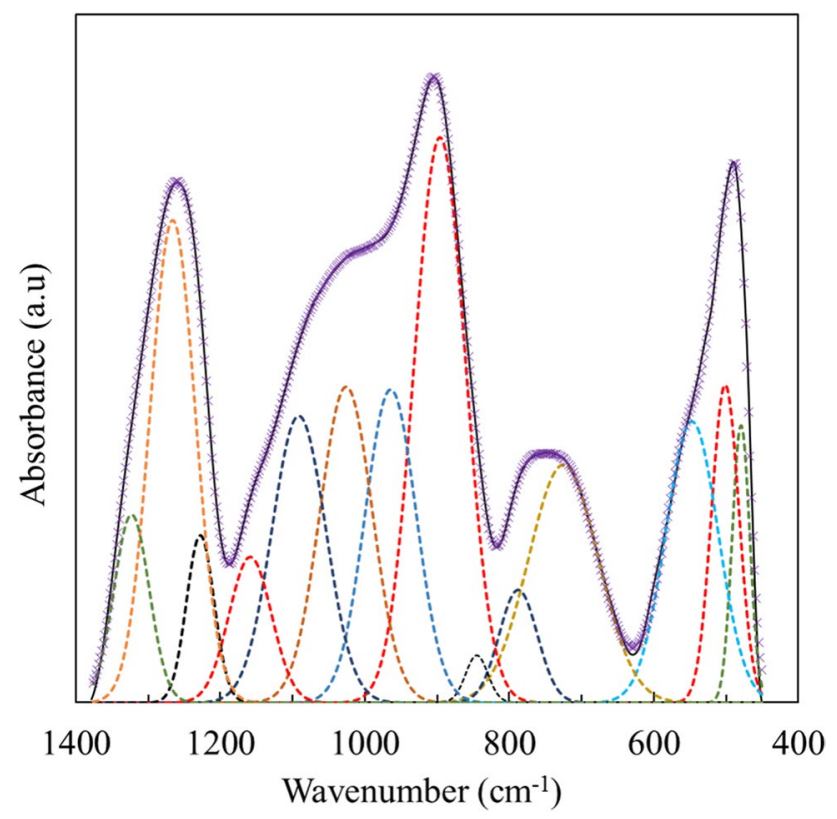

Fig. 4 The deconvolution of the IR spectrum of $30 \mathrm{ZnO}$ mol\% sample

double-bonded with the phosphate ion. The structure of $\mathrm{PO}_{4}$ tetrahedra can be found in many structural units described as $Q^{\mathrm{n}}$ where $\mathrm{n}$ is the number of nonbridging oxygen in the $\mathrm{PO}_{4}$ [23]. The addition of modifier oxide, metal oxide (M), replaces $\mathrm{P}-\mathrm{O}-\mathrm{P}$ bond by $\mathrm{M}-\mathrm{O}-\mathrm{P}$ bondforming single-bonded nonbridging oxygen.

By increasing the ratio of the modifier, the consistencies of the chains break down and depolymerize changing $\mathrm{Q}^{3}$, $\mathrm{Q}^{2}$, and $\mathrm{Q}^{1}$ units into $\mathrm{Q}^{0}$. Previous studies on sodium phosphate glasses $\left(\mathrm{Na}_{2} \mathrm{O}=30-50 \mathrm{~mol} \%\right)$ [24-26] proved that replacing $\mathrm{P}_{2} \mathrm{O}_{5}$ by $\mathrm{Na}_{2} \mathrm{O}$ changed the intermediate-range order of the glass matrix. Depolymerization increases by increasing $\mathrm{Na}_{2} \mathrm{O}$ content as a result; the compact glass matrix is gradually increased. Also, modifier cations ( $\mathrm{Zn}$, $\mathrm{Na}$ ) are presumed to be located between the nonbridging oxygens forming considerably weak ionic bonds between the strong covalent bonds within the chains. Other $\left(\mathrm{PO}_{4}\right)^{3}$ groups are cross-linked to these chains by sharing three corners by oxygen polyhedra containing the modifier ions [27]. The interpretation of the IR spectra of the samples under investigation can be summarized as the following [24-26, 28-37].

The band around $480 \mathrm{~cm}^{-1}$ is assigned to the bending vibration of $\mathrm{O}-\mathrm{P}-\mathrm{O}$ units, $\delta\left(\mathrm{PO}_{4}\right)$ modes of $\left(\mathrm{PO}_{2}\right)$ in chain groups. The band centered at about $502 \mathrm{~cm}^{-1}$ is assigned to the fundamental frequency of $\left(\mathrm{PO}_{4}\right)^{3-}$ or harmonic of $\mathrm{P}=\mathrm{O}$ bending vibrations. The band around $548 \mathrm{~cm}^{-1}$ is described as $\mathrm{O}=\mathrm{P}-\mathrm{O}$ bending vibrations. The peaks at 728 and $785 \mathrm{~cm}^{-1}$ may be due to symmetric stretching vibrations of $\mathrm{P}-\mathrm{O}-\mathrm{P}$ rings. The band at $898 \mathrm{~cm}^{-1}$ could be attributed to asymmetric stretching vibrations of $\mathrm{P}-\mathrm{O}-\mathrm{P}$ bonds linked with linear metaphosphate chain. The bands at 989 , 1083 , and $1156 \mathrm{~cm}^{-1}$ could be assigned to the asymmetric stretching vibration of $\mathrm{P}-\mathrm{O}-\mathrm{P}$ bonds linked with large metaphosphate ring, small metaphosphate rings, and bridges in pyrophosphate, respectively. $1252 \mathrm{~cm}^{-1}$ ascribed to the asymmetric stretch of doubly bonded oxygen modes, $\mathrm{v}_{\mathrm{as}}(\mathrm{P}=\mathrm{O})$. The band at $1312 \mathrm{~cm}^{-1}$ is attributed to the stretching of $\mathrm{P}=\mathrm{O}$ modes.

By increasing the $\mathrm{ZnO}$ content, the bands at 480 and 502 relative intensity increase in sample $x=2.5$ then decrease with shifting towards lower frequency, which suggests the breakdown of the $\mathrm{O}-\mathrm{P}-\mathrm{O}$ bonds with the increment of $\mathrm{ZnO}$ content in the glass. The bands located between 400 and $600 \mathrm{~cm}^{-1}$ may be attributed to the bending vibrations of bridging phosphorous [26].

As seen from Fig. 3, there is a new absorption weak band around $500 \mathrm{~cm}^{-1}$. It is suggested that the band in the region below $600 \mathrm{~cm}^{-1}$ is characteristic of $\mathrm{Zn}-\mathrm{O}$ vibrations [38]. It is presumed that the stretching band corresponding to bridging oxygen $\mathrm{P}-\mathrm{O}-\mathrm{Zn}$ bonds might be located near $1100 \mathrm{~cm}^{-1}$ similar to that of S-P-O glasses proposed by Day et al. [39] and it may be buried in the dominant $\mathrm{P}^{-\mathrm{O}^{-}}$stretching band which is a broad region. The absorption band at $1260 \mathrm{~cm}^{-1}$ which is attributed to the nonbridging oxygen $\mathrm{P}=\mathrm{O}$ decreased with the addition of $\mathrm{Zn}$ oxide as shown in 
Fig. 5. This decrease is associated with the increasing band at $1100 \mathrm{~cm}^{-1}$.

From this result, the zinc oxide may breakdown the nonbridging bonds $\mathrm{P}=\mathrm{O}$ and convert to a bridging bond $\mathrm{Zn}-\mathrm{O}$ $\mathrm{P}$ which is more water-resistant than $\mathrm{P}-\mathrm{O}-\mathrm{P}$ and $\mathrm{P}-\mathrm{O}^{-} \mathrm{Zn}^{+}$. This means that the $\mathrm{ZnO}$ can play the former role in this matrix in case of decrease in the $\mathrm{P}_{2} \mathrm{O}_{5}$ content, and this result agrees with the formation of crystalline phases with different formulas as discussed above in "X-ray diffraction results" section.

\section{Density and molar volume}

Figure 6 shows a slightly linear increase in density and a decrease in molar volume of $(55-x) \mathrm{P}_{2} \mathrm{O}_{5} \cdot(30+x)$ $\mathrm{ZnO} .15 \mathrm{Na}_{2} \mathrm{O}$ glass-ceramics corresponding to the increase of $\mathrm{ZnO} \mathrm{mol \%}$. The increase in density reflects the high packing of structural units when replacing $\mathrm{P}_{2} \mathrm{O}_{5}$ by $\mathrm{ZnO}$. It is also revealed that the modified structural units related to $\mathrm{Zn}^{2+}$ ions such as $\mathrm{P}_{-} \mathrm{O}^{-} \mathrm{Zn}^{+}$and $\mathrm{Zn}-\mathrm{O}-\mathrm{P}$ units are denser than $\mathrm{P}-\mathrm{O}-\mathrm{P}$ and the unit related to $\mathrm{Na}^{+}$ions. This factor acts in the direction of decreasing the molar volume when increasing $\mathrm{ZnO}$ content. Another factor may cause the increase in density with increasing $\mathrm{ZnO}$ content, and this factor is related to the field strength of the $\mathrm{Zn}^{+2}$ ions.

\section{Optical band gap (direct and indirect) and Urbach energy}

Optical absorption spectra of the prepared samples in infrared, optical, and UV range are shown in Fig. 7. The prepared zinc phosphate samples showed a wide range of transparency with no absorption peaks in the visible and infrared

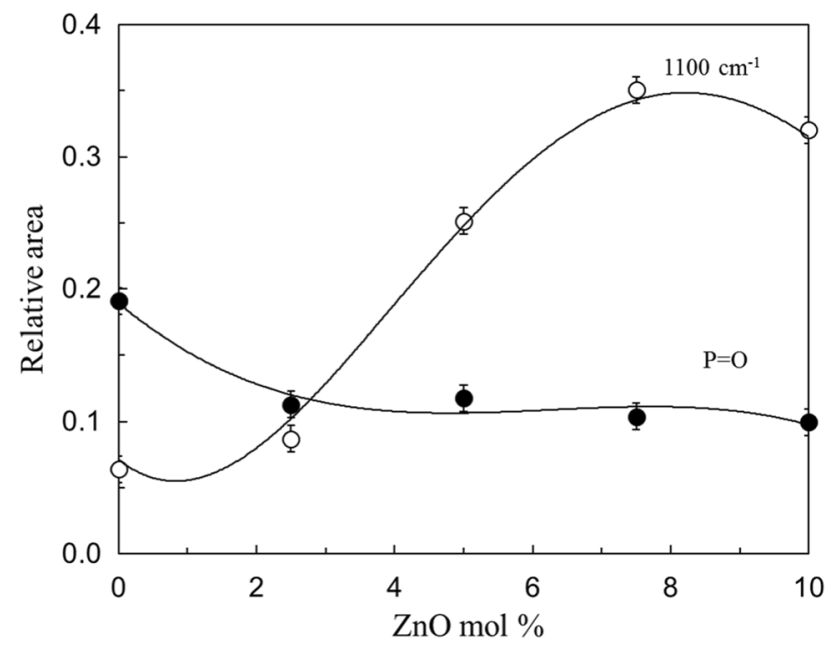

Fig. 5 Relative area of bridging oxygen P-O-Zn bonds $\left(1100 \mathrm{~cm}^{-1}\right)$ and nonbridging oxygen $\mathrm{P}=\mathrm{O}\left(1260 \mathrm{~cm}^{-1}\right)$ as a function of $\mathrm{ZnO}$ content

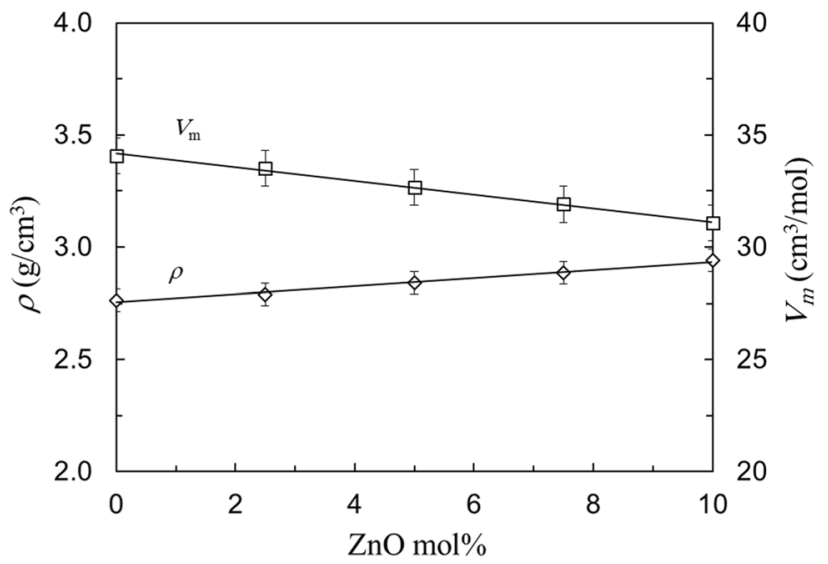

Fig. 6 Dependence of density and molar volume on the variation of $\mathrm{ZnO}$ content

range, which is one of the main aspects of phosphate glasses $[35,40,41]$. The absorption edge, cut-off, near UV range is due to the transition between valance band and conduction band, i.e., energy gap. The cut-off has two regions with different slopes indicating the presence of two transitions of the samples, direct and indirect transitions. However, the absorption edge wavelength shows a red shift with increasing the $\mathrm{ZnO}$ content in the samples.

The absorption coefficient $(\alpha)$ can be calculated by the relation [42]:

$\alpha(v)=\frac{1}{t} \log \frac{I_{0}}{I}$

where $\frac{I_{0}}{I}$ corresponds to the absorbance near the edge and $t$ is sample thickness.

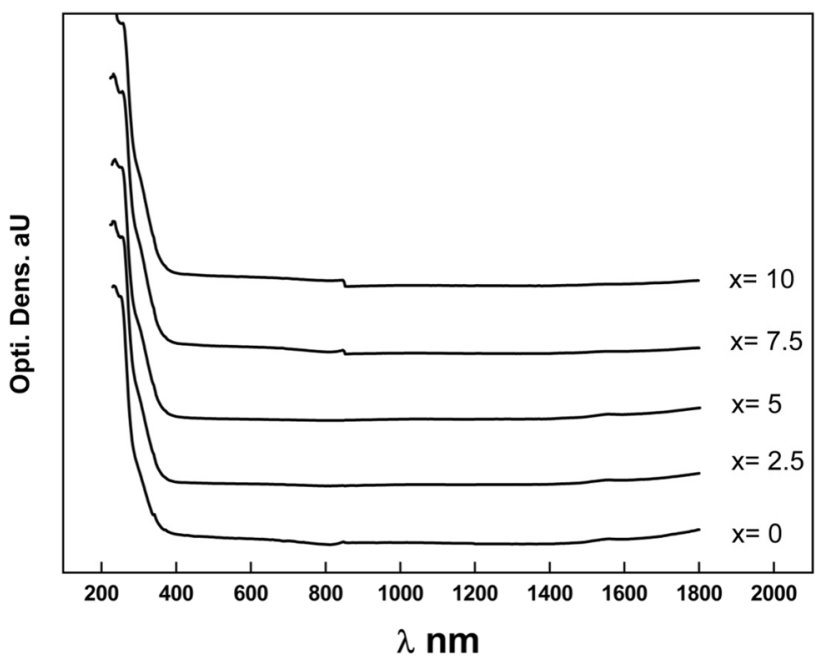

Fig. 7 Optical density of the prepared samples as a function of $\mathrm{ZnO}$ content 
By calculating the absorption coefficient, the optical band gap can be calculated using Mott-Davis relation [43]:

$\alpha(v)=B \frac{\left(h v-E_{\mathrm{opt}}\right)^{n}}{h v}$

where $E_{\text {opt }}$ is the optical band gap energy, $B$ is energy independent constant, and $n$ is a constant following the values $2,3,1 / 2$, and $1 / 2$ depending on direct and indirect intraband transitions. The indirect band gap is the common transition in glass material due to the amorphous nature of the glass composition, while the direct band gap transition is common in crystalline materials. Al-Ani and Higazy [44] show that phosphate-doped $\mathrm{MgO}$ glass has shown two-band transition direct and indirect with an indirect transition at lower energies ranging between 3.71 and $3.48 \mathrm{eV}$ and a direct transition ranging between 4.6 and $3.92 \mathrm{eV}$ which is suggested to be the case in this work due to the shape of the absorption edge regions.

Both direct and indirect band gaps were calculated for the prepared samples by extrapolating the linear part of the plots of $(\alpha h v)^{2}$ and $(\alpha h v)^{1 / 2}$, respectively, as a function of photon energy $h v$, Tuac's plot, the direct and indirect optical band gap can be obtained, as shown in Figs. 8 and 9, respectively. The calculated indirect band gap decreases with increasing zinc content as a general trend. This may be due to the addition of the zinc alters the internal glass-ceramic structure by reducing the cross-linking oxygen which increases the compactness of the system. Jlassi et al. [45] indicated that the increase in band gap energy of the phosphate glass by adding modifiers could be related to the increase of the crosslinking density in the glassy matrix. The band tail width of the absorption spectra can also provide information about a possible change in the glass structure [43]. At lower values

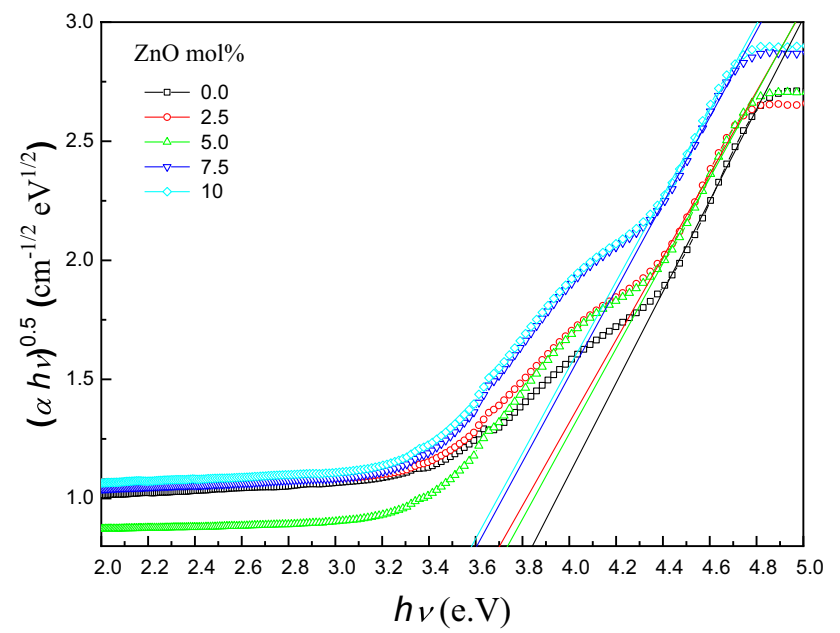

Fig. 8 Tauc's plot (indirect band gap) zinc sodium phosphate glassceramics nano composite

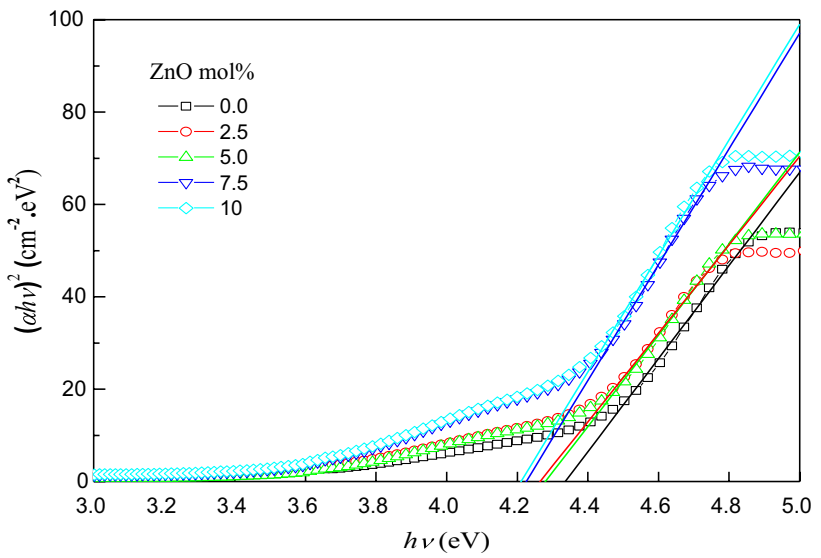

Fig. 9 Tauc's plot (direct band gap) zinc sodium phosphate glassceramics nano composite

of absorption coefficient band tail, $\Delta E$ is related to $\alpha(v)$ by exponential relation [46]:

$\alpha(v)=\alpha_{0} \exp \left(\frac{h v}{\Delta E}\right)$

where $\Delta E$ is the Urbach energy, $\alpha_{\mathrm{o}}$ is a constant, and $h v$ is the photon energy. Urbach energy indicates the width of the band tail of the localized states in the band gap. Figure 10 shows the relation between $\ln \alpha$ and $h v$, Urbach plot, for the prepared samples. $\Delta E$ can be determined by the reciprocal of the slope in the above relation. The calculated values are listed in Table 1.

By increasing zinc content, the band tail width showed an opposite trend to band gap, i.e., increase with increasing the zinc content. The increase in band tail width indicates the addition of localized states by increasing the zinc content. This may be due to the creation of defects by adding

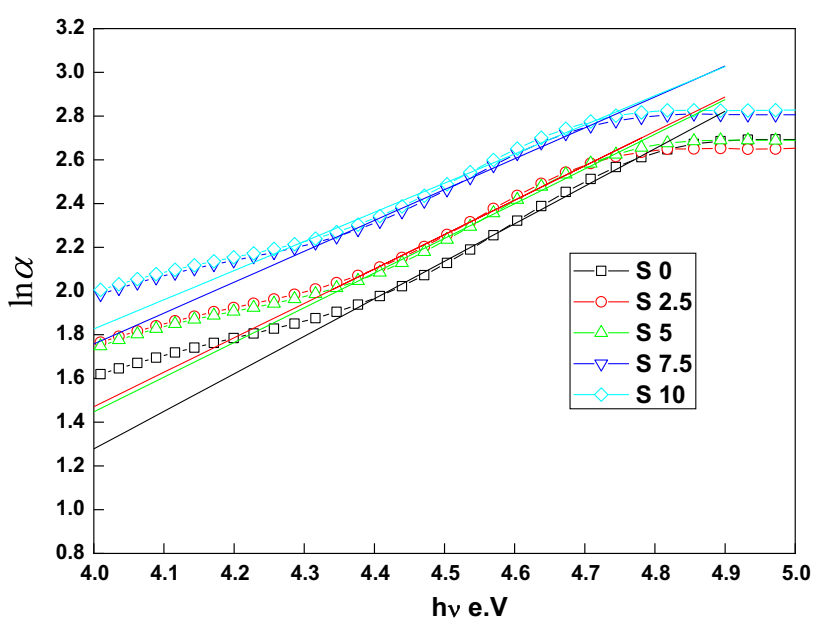

Fig. 10 Urbach energy for the prepared glass-ceramics nano composite 
Table 1 The optical band gap (direct and indirect), crystal size, and Urbach energy of the prepared glass-ceramic

\begin{tabular}{lllll}
\hline $\mathrm{ZnO}$ & $E_{\mathrm{g} \text { indirect }}( \pm 0.05) \mathrm{eV}$ & $E_{\mathrm{g} \text { direct }}( \pm 0.05) \mathrm{eV}$ & $E_{\mathrm{U}}( \pm 0.05) \mathrm{eV}$ & $\begin{array}{l}\mathrm{Crystal} \text { size }( \pm 0.1) \\
(\mathrm{nm})\end{array}$ \\
\hline 0 & 3.42 & 4.34 & 0.58 & 22.75 \\
2.5 & 3.24 & 4.26 & 0.61 & 27.29 \\
5.0 & 3.28 & 4.28 & 0.63 & 40.18 \\
7.5 & 3.16 & 4.24 & 0.69 & 34.42 \\
10 & 3.13 & 4.20 & 0.73 & 29.18 \\
\hline
\end{tabular}

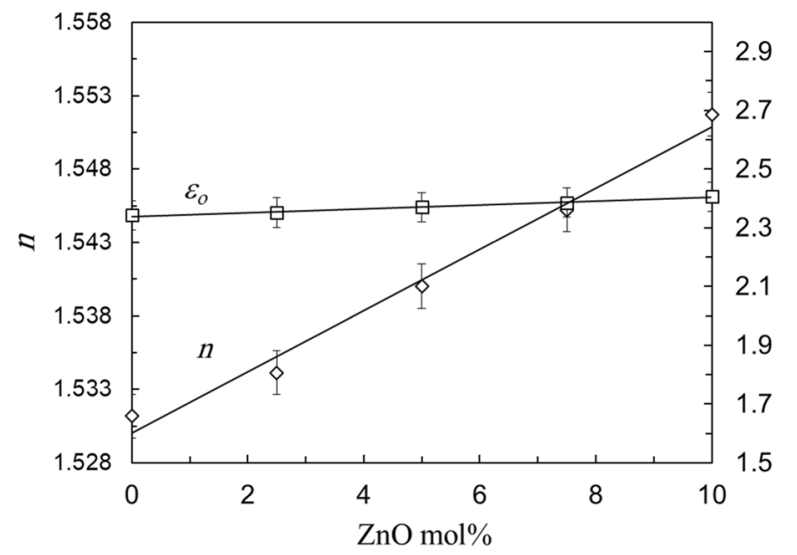

Fig. 11 Refractive index $(n)$ and optical dielectric constant as a function of $\mathrm{ZnO}$ content

modifiers to the glass-ceramics network, which increases the number of the localized states in the band gap due to the formation of crystalline phases, and this result agrees with the XRD and FTIR spectroscopy results [46-48].

Refractive index $(n)$ is very important for optical applications of the glasses. The linearity of the refractive index is correlated to the energy band gap and the density of the oxide glasses in density range $1-3 \mathrm{gm} / \mathrm{cm}^{3}$, and $n$ can be calculated by the relation $[49,50]$ :

$n_{r}=\frac{D+10.4}{8.6}$

Optical dielectric constant can be calculated from refractive index $\left(\varepsilon_{0}=n^{2}\right)$ [50]. Hence, the expression of the Penn model can be formulated in relation with the refractive index $[49,50]$.

Figure 11 shows the variation of refractive index and optical dielectric constant of the prepared samples with $\mathrm{ZnO}$ content. The refractive index showed a linear increase with increasing $\mathrm{ZnO}$ content. ( $n$ ) showed slightly increased between 1.53 for base glass and 1.55 for high $\mathrm{ZnO}$ content depending on the role of $\mathrm{ZnO}$ in the glass matrix. This is an indication of the increase of compactness of the system which agrees with increasing of crystallinity that observed in XRD results. On the other hand, the optical dielectric

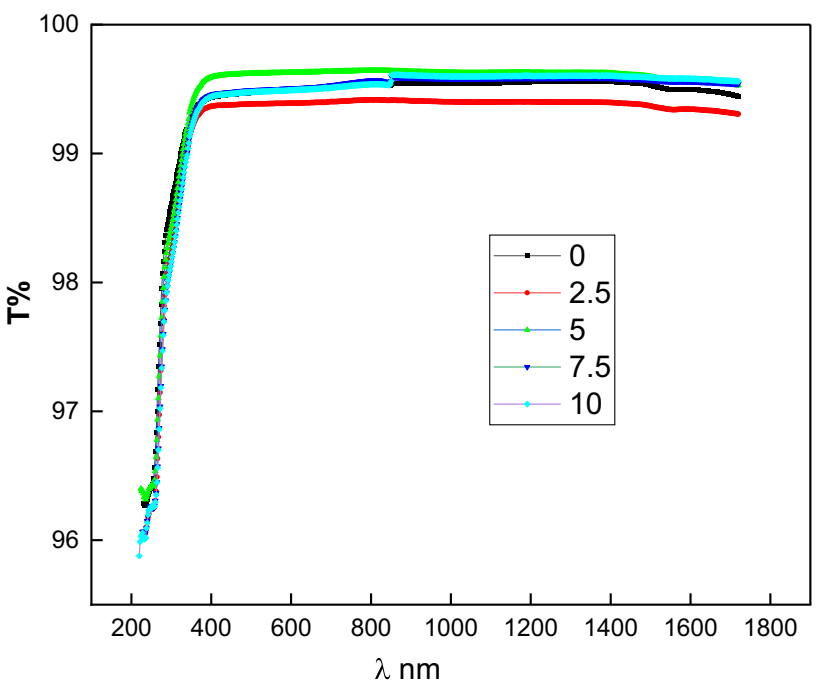

Fig. 12 Optical transmission of zinc sodium phosphate glass-ceramics nano composite

constant of all the samples is varying from 2.33 to 2.39 , which is almost independent of the concentration of $\mathrm{ZnO}$ content. The slight increase in the optical dielectric constant causes a reduction in the optical band gap.

Visibility is transparent for all of compositions $(X=0-10 \mathrm{~mol} \%) \mathrm{ZnO}$. Although nearly all compositions contain some specific crystalline nano structure, this means that the investigated samples lie in the region of transparent glass-ceramic (TGC). This argument is supported by the limited changes between refractive index with $\mathrm{ZnO}$ content, and $(n)$ changes by only 0.04 for $10 \mathrm{~mol} \% \mathrm{ZnO}$ sample. Figure 12 shows UV/Vis transmission spectra for the prepared samples. All of composition is regard as transparent ( $90 \%)$. This insures the phenomenon (TGC).

\section{Conclusion}

Phosphate-based glass system with the composition (55- $x$ ) $\mathrm{P}_{2} \mathrm{O}_{5} \cdot(30+x) \mathrm{ZnO} .15 \mathrm{Na}_{2} \mathrm{O}$ where $x=0,2.5,5,7.5$, and 10 was prepared with the conventional melt quenching method. The crystallinity of the samples increases with increasing 
the $\mathrm{ZnO}$ content up to $7.5 \mathrm{~mol} \%$. By increasing the $\mathrm{ZnO}$ content, the crystallinity decreases due to disillusion of the crystalline phase in the glass matrix. IR measurements show that the zinc oxide may breakdown the nonbridging bonds $\mathrm{P}=\mathrm{O}$ and convert to a bridging bond $\mathrm{Zn}-\mathrm{O}-\mathrm{P}$ which is more water-resistant than $\mathrm{P}-\mathrm{O}-\mathrm{P}$ and $\mathrm{P}-\mathrm{O}^{-} \mathrm{Zn}^{+}$. The density of the samples increases with increasing $\mathrm{ZnO}$ while molar volume decreases. The optical absorption of the samples under investigation shows a high range of transparency in the optical and IR range. The calculated optical band gap decreases with increasing $\mathrm{ZnO}$ content with the range 3.42 and $3.13 \mathrm{eV}$ for indirect transition and ranging between 4.34 and $4.20 \mathrm{eV}$ for direct transition. These results suggest the suitability of these samples for many glass-ceramics applications such as a host material for rare-earth ions and/or transition metals used in solid-state lasers and other optical applications.

Author contribution All listed authors contributed to the study conception and design. Samples preparation, data collection, and analysis were performed. The first draft of the manuscript was written by Dr. Mohammed Abd Elaity Farag and all authors commented on previous versions of the manuscript. All authors read and approved the final manuscript.

Funding Open access funding provided by The Science, Technology \& Innovation Funding Authority (STDF) in cooperation with The Egyptian Knowledge Bank (EKB).

Availability of data and materials Not applicable.

\section{Declarations}

Ethics approval and consent to participate Not applicable.

Consent to participate Not applicable.

Consent for publication Not applicable.

Competing interests The authors declare no competing interests.

Research involving human participants and/or animals Not applicable.

Open Access This article is licensed under a Creative Commons Attribution 4.0 International License, which permits use, sharing, adaptation, distribution and reproduction in any medium or format, as long as you give appropriate credit to the original author(s) and the source, provide a link to the Creative Commons licence, and indicate if changes were made. The images or other third party material in this article are included in the article's Creative Commons licence, unless indicated otherwise in a credit line to the material. If material is not included in the article's Creative Commons licence and your intended use is not permitted by statutory regulation or exceeds the permitted use, you will need to obtain permission directly from the copyright holder. To view a copy of this licence, visit http://creativecommons.org/licenses/by/4.0/.

\section{References}

1. Gonçalves, M.C., Santos, L.F., Almeida, R.M.: Rare-earth-doped transparent glass ceramics. C. R. Chim. 5(12), 845-854 (2002)

2. Karabulut, M., Melnik, E., Stefan, R.: Mechanical and structural properties of phosphate glasses. J. Non-Cryst. Solids 288, 8-17 (2001)

3. El-Desoky, M.M., Ibrahim, F.A., Mostafa, A.G., Hassaan, M.Y.: Effect of nanocrystallization on the electrical conductivity enhancement and Mo"ssbauer hyperfine parameters of iron based glasses. Mater. Res. Bull. 45, 1122-1126 (2010)

4. Stoch, P., Ciecinska, M.: Thermochemistry of phosphate glasses for immobilization of dangerous waste. J. Therm. Anal. Calorim 108, 705-709 (2012)

5. Bitar, M., Knowles, J.C., Lewis, M.P., Salih, V.: Soluble phosphate glass fibres for repair of bone-ligament interface. J. Mater. Sci.Mater. M. 16, 1131-1136 (2005)

6. Lee, Y.S., Kang, W.H.: Structure and dissolution properties of phosphate glasses for glass fertilizer. Mater. Sci. Forum 449-452, 737-740 (2004)

7. Cacaina, D., Simon, S.: Calcium influence on dissolution rates of potassium phosphate glasses. J. Optoelectron. Adv. Mater. 5, 191-194 (2003)

8. Langar, A., Sdiri, N., Elhouichet, H., Ferid, M.: Conductivity and dielectric behavior of $\mathrm{NaPO}_{3}-\mathrm{ZnO}-\mathrm{V}_{2} \mathrm{O}_{5}$ glasses. J. Alloys Compd. 590, 380-387 (2014)

9. Jlassi, N., Sdiri, H., Elhouichet, M.: Ferid, Raman and impedance spectroscopy methods of $\mathrm{P}_{2} \mathrm{O}_{5}-\mathrm{Li}_{2} \mathrm{O}-\mathrm{Al}_{2} \mathrm{O}_{3}$ glass system doped with $\mathrm{MgO}$. J. Alloys Compd. 645, 125-130 (2015)

10. Langar, A., Bouzidi, C., Elhouichet, H., Ferid, M.: Er-Yb codoped phosphate glasses with improved gain characteristics for an efficient $1.55 \mu \mathrm{m}$ broadband optical amplifiers. J Lumin 148, 249-255 (2014)

11. Saada, M., Stamboulia, W., Sdiria, N., Elhouichet, H.: Effect of mixed sodium and vanadium on the electric and dielectric properties of zinc phosphate glass. Mater. Res. Bull. 89, 224-231 (2017)

12. Murthy, D.V.R., Sasikala, T., Jamalaiah, B.C., Babu, A.M., Kumar, J.S., Jayasimhadri, M., Moorthy, L.R.: Investigation on luminescence properties of $\mathrm{Nd}^{3+}$ ions in alkaline-earth titanium phosphate glasses. Opt. Commun. 284(2), 603-607 (2011)

13. Liu, C.X., Xu, J., Fu, L.L., Zheng, R.L., Zhou, Z.G., Li, W.N., Guo, H.T., Lin, S.B., Wei, W.: Fabrication and characterization of carbon/oxygen-implanted waveguides in $\mathrm{Nd} 3+$-doped phosphate glasses. Opt. Eng. 54(6), 067106 (2015)

14. Mercier, C., Palavit, G., Montagne, L., Follet-Houttemane, C.: A survey of transition-metal-containing phosphate glasses. C. R. Chimie 5, 693-703 (2002)

15. Chahine, A., Et-Tabirou, M., Pascal, J.L.: FTIR and Raman spectra of the $\mathrm{Na}_{2} \mathrm{O}-\mathrm{CuO}-\mathrm{Bi}_{2} \mathrm{O}_{3}-\mathrm{P}_{2} \mathrm{O}_{5}$ glasses. Mater. Lett. 58, 2776-2780 (2004)

16. Hejda, P., Holubová, J., Černošek, Z., Černošková, E.: The structure and properties of vanadium zinc phosphate glasses. J. NonCryst. Solids 462, 65-71 (2017)

17. Franks, K., Abrahams, I., Georgiou, G.: Investigation of thermal parameters and crytallisation in a ternary $\mathrm{CaO}-\mathrm{Na}_{2} \mathrm{O}-\mathrm{P}_{2} \mathrm{O}_{5}$-based glass system. Biomaterials 22, 497-501 (2001)

18. Abdelghany, A.M., ElBatal, F.H., ElBatal, H.A., EzzElDin, F.M.: Optical and FTIR structural studies of $\mathrm{CoO}$-doped sodium borate, sodium silicate and sodium phosphate glasses and effects of gamma irradiation - a comparative study. J. Molecular Structure 1074, 503-510 (2014)

19. Doweidar, H., Moustafa, Y.M., El-Egili, K., Abbas, I.: Infrared spectra of $\mathrm{Fe}_{2} \mathrm{O}_{3}-\mathrm{PbO}-\mathrm{P}_{2} \mathrm{O}_{5}$ glasses. Vib. Spectrosc. 37(1), 91-96 (2005) 
20. Moustafa, Y.M., Doweidar, H., El-Damrawi, G.: Utilisation of infrared spectroscopy to determine the fraction of the four coordinated borons in borate glasses. Phys Chem Glasses 35(2), 104106 (1994)

21. Aly Saeed, M.A., Farag, W.A.: Abu-raia, Er3+ ion doped low phonon energy glass as a white light emitter Egypt. J. Solids 43, 97-110 (2021)

22. Scherrer P., Determination of the size and internal structure of colloidal particles using X-rays, Göttinger Nachrichten Gesell., 2 (98) (1918) German.

23. Brow, R.K.: Review: The structure of simple phosphate glasses. J. Non-Cryst. Solids 263\&264, 1 (2000)

24. Wong, J., Angell, C.A.: Glass structure by spectroscopy. Marcel Dekker, NewYork (1976)

25. Efimov, A.M.: IR fundamental spectra and structure of pyrophosphate glasses along the $2 \mathrm{ZnO} \cdot \mathrm{P}_{2} \mathrm{O}_{5}-2 \mathrm{Me}_{2} \mathrm{O} \cdot \mathrm{P}_{2} \mathrm{O}_{5}$ join (Me being $\mathrm{Na}$ and Li). J. Non-Cryst. 209(3), 209-226 (1997)

26. Moustafa, Y.M., El-Egili, K.: Infrared spectra of sodium phosphate glasses. J. Non-Cryst. Solids 240, 144 (1998)

27. Lu, M., Wang, F., Chen, K., Dai, Y., Liao, Q., Zhu, H.: The crystallization and structure features of barium-iron phosphate glasses. Spectrochim. Acta Part A Mol. Biomol. Spectrosc. 148, 1-6 (2015)

28. Misbah, M.H., Doweidar, H., El-Egili, K., El-Damrawi, G., ElKemary, M.: Structure and some properties of $\mathrm{xBaO} \cdot(50-\mathrm{x}) \mathrm{PbO}$. $50 \mathrm{P}_{2} \mathrm{O}_{5}$ glasses. J. Non-Cryst. Solids 534, 119945 (2020)

29. El-Damrawi, G., Hassan, A., Doweidar, H., Shaboub, A.: Structural studies on $\mathrm{Ag}_{2} \mathrm{O}-\mathrm{P}_{2} \mathrm{O}_{5}$ glasses. New J. Glass Ceram. 7(03), 77 (2017)

30. Efimov, A.M.: IR fundamental spectra and structure of pyrophosphate glasses along the $2 \mathrm{ZnO} \cdot \mathrm{P}_{2} \mathrm{O}_{5}-2 \mathrm{Me}_{2} \mathrm{O} \cdot \mathrm{P}_{2} \mathrm{O}_{5}$ join (Me being $\mathrm{Na}$ and Li). J. Non-Cryst. Solids 209(3), 209-226 (1997)

31. El-Egili, K., Doweidar, H., Moustafa, Y.M., Abbas, I.: Structure and some physical properties of $\mathrm{PbO}-\mathrm{P}_{2} \mathrm{O}_{5}$ glasses. Physica B 339(4), 237-245 (2003)

32. Shahboub, A., El Damrawi, G., Saleh, A.: A new focus on the role of iron oxide in enhancing the structure and shielding properties of $\mathrm{Ag}_{2} \mathrm{O}-\mathrm{P}_{2} \mathrm{O}_{5}$ glasses. Eur. Phys. J. Plus 136(9), 1-17 (2021)

33. Elbakey, A.A., Farag, M.A., El-Okr, M., Elrasasi, T.Y., El-Mansy, M.K.: Preparation and characterization of phosphate glasses Codoped with rare earth ions. Egypt. J. Chem. 63(5), 1955-1964 (2020)

34. Shapaan, M., El-Badry, S.A., Mostafa, A.G., Hassaan, M.Y., Hazzaa, M.H.: Structural and electric-dielectric properties of some bismuth-phosphate glasses. J. Phys. Chem. Solids 73, 407-417 (2012)

35. Y. Elbashar, S. Hussien, J. Khaliel, M. Mohamed, A. Omran, R. Ibrahem, W. Rashidy, A. Abdelrahaman, H. Hassan, Infrared spectroscopic analysis of cadmium doped sodium zinc phosphate glass matrix. Nonlinear Optics, Quantum Optics: Concepts in Modern Optics, 54 (2021).

36. Alibakhshi, E., Ghasemi, E., Mahdavian, M.: Sodium zinc phosphate as a corrosion inhibitive pigment. Prog. Org. Coat. 77(7), 1155-1162 (2014)

37. W. Jian Dong, L. Da, L. Jin Ku, Y. Xiao Hong, H. Jia Luo, L. Yi, One-step preparation and characterization of zinc phosphate nanocrystals with modified surface. Soft Nanoscience Letters, 2011.

38. Hurt, J.C., Phillips, C.J.: Structural role of zinc oxide in glasses in the system $\mathrm{Na}_{2} \mathrm{O}-\mathrm{ZnO}-\mathrm{SiO}_{2}$. J. Am. Ceram. Sot. 53, 269-273 (1970)

39. Xu, X.J., Day, D.E.: Properties and structure of Sn-POF glasses. Phys Chem Glasses 31(5), 183-187 (1990)

40. Bianca Paula de Sousa, Lia Mara Marcondes, Sergio Alexandre Maestri, Cristiano Ramos da Cunha, Fabia Castro Cassanjes, Gael Yves Poirier, Phosphate glasses with high tantalum oxide contents: thermal, structural and optical properties, Materials Chemistry and Physics 239 (2020) 121996.

41. Al-Ani, S.K.J., Higazy, A.A.: Study of optical absorption edges in $\mathrm{MgO}-\mathrm{P}_{2} \mathrm{O}_{5}$ glasses. J Mater Sci 26, 3670 (1991)

42. Farouk, M., Abd El-Maboud, A., Ibrahim, M., Ratep, A., Kashif, I.: Optical properties of lead bismuth borate glasses doped with neodymium oxide. Spectrochim. Acta. Part A 149, 338-342 (2015)

43. Mott, N.F., Davis, E.A.: Conduction in non-crystalline systems. Philos. Mag. 17, 1269 (1968)

44. Jlassi, I., Elhouichet, H., Ferid, M.: Influence of $\mathrm{MgO}$ on structure and optical properties of alumino-lithium-phosphate glasses. Phys. E 81, 219 (2016)

45. Urbach, F.: Phys. The long-wavelength edge of photographic sensitivity and of the electronic absorption of solids. Rev 92, 1324 (1953)

46. Farouk, M., Samir, A., El Okr, M.: Effect of alkaline earth modifier on the optical and structural properties of $\mathrm{Cu}^{2+}$ doped phosphate glasses as a bandpass filter. Physica B 530, 43-48 (2018)

47. Seema, D., Khasa, S., Dahiya, M.S., Yadav, A., Agarwal, A., Dahiya, S.: Journal of Asian Ceramic Societies 3, 234-239 (2015)

48. Told, F.: Systematic analysis of optical glasses concerning their refractive indices and densities. Glastechnische Berichte (Germany) 33, 303-335 (1960)

49. AbuShanab, W.S., Moustafa, E.B., Hammad, A.H., Ramadan, R.M., Wassel, A.R.: Enhancement the structural, optical, and nonlinear optical properties of cadmium phosphate glasses by nickel ions. J. Mater. Sci.: Mater. Electron. 30, 18058-18064 (2019)

50. Goodman, B.A., Severino, J.F., Pirker, K.F.: Reactions of green and black teas with $\mathrm{Cu}$ (II). Food Funct. 3, 399-409 (2012)

Publisher's note Springer Nature remains neutral with regard to jurisdictional claims in published maps and institutional affiliations. 